\section{Urban Lead Poisoning and Medical Geology: An Unfinished Story}

\author{
Gabriel M. Filippelli, gfilippe@iupui.edu, Mark A.S. Laidlaw, Jennifer C. Latimer, \\ and Robyn Raftis, Indiana University-Purdue University Indianapolis, Department of \\ Geology, 723 W. Michigan St., Indianapolis, Indiana 46202-5132, USA
}

\begin{abstract}
The intersection between geological sciences and human health, termed medical geology, is gaining significant interest as we understand more completely coupled biogeochemical systems. An example of a medical geology problem largely considered solved is that of lead $(\mathrm{Pb})$ poisoning. With aggressive removal of the major sources of $\mathrm{Pb}$ to the environment, including Pb-based paint, leaded gasoline, and lead pipes and solder, the number of children in the United States affected by $\mathrm{Pb}$ poisoning has been reduced by $80 \%$, down to a current level of $2.2 \%$. In contrast to this national average, however, about $15 \%$ of urban children exhibit blood $\mathrm{Pb}$ levels above what has been deemed "safe" (10 $\mu \mathrm{g}$ per deciliter); most of these are children of low socioeconomic-status minority groups. We have analyzed the spatial relationship between $\mathrm{Pb}$ toxicity and metropolitan roadways in Indianapolis and conclude that $\mathrm{Pb}$ contamination in soils adjacent to roadways, the cumulative residue from the combustion of leaded gasoline, is being remobilized. Developing strategies to remove roadway $\mathrm{Pb}$ at the source is a matter of public health and social justice, and constitutes perhaps the final chapter in this particular story of medical geology.
\end{abstract}

\section{INTRODUCTION}

The industrial age has seen a number of technological advances that have had unforeseen environmental and human consequences. The awareness of the severe neurotoxicity of lead $(\mathrm{Pb})$ in humans, for example, provoked a number of regulatory measures, including phase-out of $\mathrm{Pb}$ as additives to gasoline, paint, water pipes, and solder, which significantly reduced the human exposure to $\mathrm{Pb}$. The end product of these actions? A reduction in $\mathrm{Pb}$ poisoning of children by $80 \%$ since the late 1970 snow $<2.2 \%$ of U.S. children between the ages of one and five are considered $\mathrm{Pb}$ poisoned (National Health and Nutrition Examination Survey [NHANES], 2003).

By all usual accounts, the recent turnaround in national health statistics related to $\mathrm{Pb}$ poisoning implies a seamless and uniform industrial and governmental response to this threat and denotes the end of $\mathrm{Pb}$ as a human health risk. Sadly, such is not the casemany urban areas still exhibit high $\mathrm{Pb}$ poisoning rates in children under age six (the most vulnerable age interval for $\mathrm{Pb}$ toxicity; Koller et al., 2004), reaching values up to $29 \%$ of the $0.5-5$ yr old population in New Orleans, Louisiana (Rabito et al., 2003), and even higher overseas (e.g., 78\% of school children in Johannesburg, South Africa are considered Pb-poisoned; Mathee et al. [2002]). Childhood $\mathrm{Pb}$ poisoning continues to be a major public health problem in income, urban, African-American children (Roberts et al., 2001). The emission control and public health strategies used in the past have not been successful at overcoming this urban poisoning remnant (Agency for Toxic Substances and Disease Registry [ATSDR], 2002), and until we fully understand the anthropogenic, geologic, and socioeconomic web that results in the poisoning of urban youth, this remains an unfinished story in the annals of medical geology.

In this paper, we introduce the historical perspective of $\mathrm{Pb}$ use, particularly in leaded gasoline, and the findings that $\mathrm{Pb}$ has significant health impacts for humans. But more importantly, we discuss how integrating geologic factors, like soil, $\mathrm{Pb}$ geochemistry and cycling, and soil moisture and resuspension, into public health practices may help to ultimately eliminate $\mathrm{Pb}$ poisoning as a human health concern. the United States, particularly for low-

\section{HISTORY}

Lead toxicity has been known for centuries, but it was not until the industrial revolution that this issue became a widespread problem. Lead is a soft and workable metal easily extracted from galena ore, characteristics that were widely exploited by preindustrial populations. The Romans developed the first large-scale quarrying and working operations for $\mathrm{Pb}$, exploiting the newly conquered Iberian Peninsula and its rich metal deposits to produce finished $\mathrm{Pb}$ used in containers, water pipes, and as a $\mathrm{Pb}$-salt preservative for wines (in which application the $\mathrm{Pb}$ becomes very bioavailable); evidence of the global impacts of this quarrying effort are seen in Greenland ice core records (Hong et al., 1994; Rosman et al., 1997).

By far the largest use of $\mathrm{Pb}$ has occurred in the industrial era, where two new applications of $\mathrm{Pb}$ were found in the twentieth century: Pb-based paints and tetraethyl/methyl additives to gasoline. Lead-based paints, which contain up to $15 \% \mathrm{~Pb}$, are extremely durable and flexible, and their use expanded dramatically during the 1920s (Fig. 1). The production and use of $\mathrm{Pb}$ for gasoline additives was spurred by the need to control the explosion of gasoline in cylinders of internal combustion engines. Thomas Midgely, an engineer for General Motors and DuPont, perfected the formulation of $\mathrm{Pb}$ additives in the 1920s, but the peak in $\mathrm{Pb}$ use for this application follows the trend in automobile use in America, with a peak closer to 1970 (Fig. 1). Midgely (ironically, also the inventor of Freon ${ }^{\circledR}$, the chlorofluorocarbon chemical implicated in stratospheric ozone loss) first developed an effective anti-knock additive using plant biomass-produced alcohol, but as this additive could be produced by any farmer and was not patentable, he was told to continue searching, eventually finding that adding $\sim 2 \% \mathrm{~Pb}$ oxides to gasoline works well. An early warning sign went up when scores of workers were severely poisoned in the 1920s by $\mathrm{Pb}$ toxicity in plants producing tetraethyl $\mathrm{Pb}$ additives, although a multi-pronged industrial cover-up limited public awareness of this situation (Markowitz and Rosner, 2002). The 


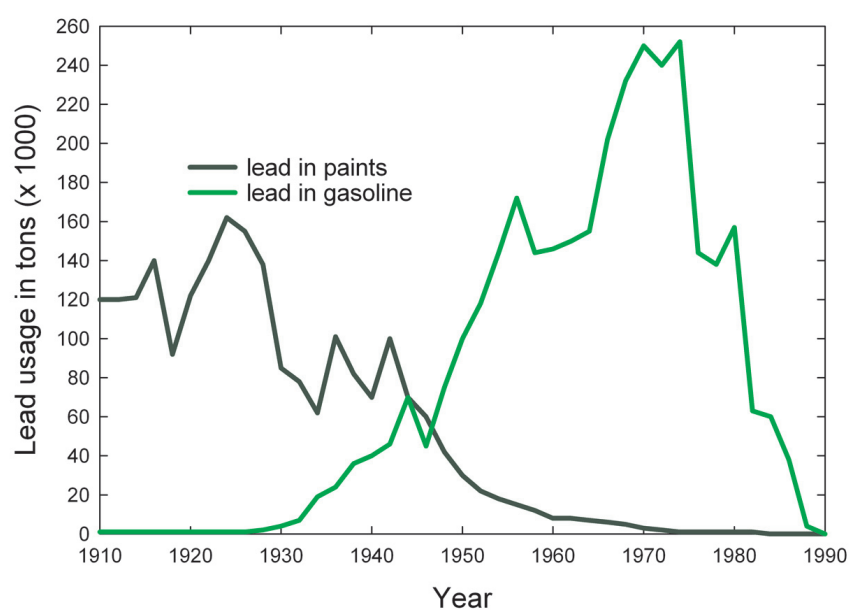

Figure 1. History of $\mathrm{Pb}$ usage in paints and gasoline during most of the twentieth century, showing the early dominance of Pb-based paints followed by the boom in transportation resulting in a high use of leaded gasoline (after Mielke, 1999). The decline after the mid-1970s was due to controls put into place to eliminate leaded gasoline.

dawn of the automobile age shelved concerns of the environmental impacts of tetraethyl $\mathrm{Pb}$ as affordable transportation dramatically altered the American landscape of the twentieth century.

Just how much the use of tetraethyl and other $\mathrm{Pb}$ impacted our environment began to be discerned in the 1950s in a laboratory at the California Institute of Technology. There, an isotope geochemist named Clair Patterson was carefully examining earth materials using new methods of mass spectrometry, with a goal of understanding the age of Earth (which, remarkably, he pinned at 4.55 Ga in 1963, nearly identical to modern estimates). He used radiogenic $\mathrm{Pb}$ isotopes for this work, and soon found that $\mathrm{Pb}$ isotopic ratios were excellent tools for fingerprinting source regions of sedimentary rocks and water bodies. One persistent problem he had in these efforts was the prevalence of contamination by anthropogenic $\mathrm{Pb}$ sources. Turning his considerable talents to this problem of contamination ended up being one of the great stories in medical geology. Patterson found that $\mathrm{Pb}$ resulting from human activity was everywhere, including water, soil, arctic ice, and most troubling, in people. Indeed, the development of $\mathrm{Pb}$ isotopic techniques has significantly enhanced our understanding of sources of additional $\mathrm{Pb}$ to the environment and cycling of $\mathrm{Pb}$ in soils (Deboudt et al., 1999; Sañudo-Wilhelmy and Gill, 1999; Kurkjian and Flegal, 2003) and in human tissues (Graziano et al., 1996; Gwiazda and Smith, 2000; Manton et al., 2000; Rothenberg et al., 2001). Showing an academic bravery just short of foolishness, Patterson not only published his troubling findings of $\mathrm{Pb}$ contamination and potential poisoning in humans in peer-reviewed scientific journals (e.g., Settle and Patterson, 1980), but he also raised the alarm to regulators, industries, and lawmakers, pointing out that the sources of this contaminant were clear and could be completely eliminated. After many well-documented attacks on his credibility, funding, and job by industry advocates (see Bill Bryson's 2003 book, A Short History of Nearly Everything, for an excellent recounting), he succeeded in convincing lawmakers to eliminate
$\mathrm{Pb}$ use in pipes, solder, and finally, in 1986, gasoline. As a measure of the value that the geological community placed on these efforts, the Geochemical Society's Environmental Geochemistry Medal is named in honor of Patterson.

\section{LEAD AND HUMAN HEALTH}

In part due to Patterson's crusade, new sources of $\mathrm{Pb}$ to the environment have been virtually eliminated in the United States and are being reduced and/or eliminated in many other countries as well. The net impact of this elimination can best be measured from a human health standpoint by the concentration of $\mathrm{Pb}$ in blood serum samples (venous blood $\mathrm{Pb}$ level). A portion of the $\mathrm{Pb}$ ingested via soil or water and/or inhaled is absorbed in the intestine and incorporated in the body. Inhalation is a minor uptake pathway and ingestion via water has largely been reduced with the replacement of $\mathrm{Pb}$ water pipes and water tanks with non- $\mathrm{Pb}$ alternatives. However, $\mathrm{Pb}$ in soil and dust continues to be a major source of exposure (Koller et al., 2004). Based on clinical trials, the portion of ingested $\mathrm{Pb}$ that is taken up in the body is typically less than 5\% for adults, whereas it is as high as 50\% for children due to their less-developed gastrointestinal pathway (Ziegler et al., 1978; Maddaloni et al., 1998).

Due to similar charges and ionic radii, $\mathrm{Pb}$ is utilized in biological processes much like $\mathrm{Ca}$, including as a critical component of converting the electrical neural signal into a chemical signal and as a component of hydroxyapatite in the production of bone material. When engaged in the former process, $\mathrm{Pb}$ does not function as a neurotransmitter, effectively creating permanent neural differentiation defects resulting in mental retardation, learning disorders, and attention deficit hyperactivity disorder (ADHD). Because of their high ingestion efficiency and the rapid neural differentiation during early brain and nervous system development, children are especially vulnerable to the permanent effects of $\mathrm{Pb}$ poisoning. When $\mathrm{Pb}$ is incorporated in bone material, the bone becomes a long-term source of $\mathrm{Pb}$ to the biological system-bone is regenerated on monthly to yearly timescales, leaking additional $\mathrm{Pb}$ into the system. For this reason, children treated by medical interventions like blood chelation may continue exhibiting toxic levels of $\mathrm{Pb}$ in their blood (Roberts et al., 2001). In summary, persistent elevated $\mathrm{Pb}$ concentration in children can create a cascade of severe and permanent mental, behavioral, and physiological problems.

The health standards for $\mathrm{Pb}$ levels in blood have been revised steadily downward over the years as medical research has determined toxicological effects of $\mathrm{Pb}$ even in low quantities. The U.S. Centers for Disease Control and Prevention (CDC) in 1991 chose $10 \mu \mathrm{g} / \mathrm{dL}$ as an initial screening level for $\mathrm{Pb}$ in children's blood, although some research suggests that levels even lower than this can cause some toxicological effects (Bernard, 2003; Brown and Meehan, 2004). The persistent presence of $\mathrm{Pb}$ in children is a public health issue of a first order. As noted earlier, as a U.S. national average, 2.2\% of children under the age of 6 exhibit blood $\mathrm{Pb}$ levels above this screening level, although this value is often above 15\% among urban youth. In a summary from a national health survey, Brody et al. (1994) state "the exposure to $\mathrm{Pb}$ at levels that may adversely affect the health of children remains a problem 
especially for those who are minority, urban, and from low-income families. Strategies to identify the most vulnerable risk groups are necessary to further reduce $\mathrm{Pb}$ exposure in the United States." Factors affecting children in this socioeconomic class include poor nutrition with the potential for pica behavior (a subconscious desire to ingest soil and dust to overcome nutritional deficits), inadequate pediatric health care, poor home maintenance with a high percentage of rental housing, a significant proportion of urban housing with high dust and dirt exposure, and relatively low awareness of the links between health and behavior.

In this paper, we use the city of Indianapolis, Indiana, a typical older midwestern United States city, to explore in detail the continuing sources and the pathways for exposure that face urban youth. Indianapolis is the 12th largest city in the country, with diversity reflecting the national average (25\% African-American and Hispanic), a significant proportion of pre-1940s housing (with Pb-based paint use), and a large interstate transportation connection downtown with a clear history of leaded gasoline use. Additionally, Indianapolis has excellent public health records from which to extract the distribution of $\mathrm{Pb}$ poisoned children. Combining information about point sources of environmental contamination, a sampling technique designed to determine more diffuse sources of soil $\mathrm{Pb}$, seasonality studies, and public health data, we demonstrate the ongoing impact that past $\mathrm{Pb}$ contamination has on the population, and provide several recommendations for determining and predicting $\mathrm{Pb}$ contamination and poisoning.

\section{METHODS}

All soil samples used in this study were collected from amalgamated sampling techniques (a $10 \mathrm{~m}$ grid with pooled surface samples of the upper 5 $\mathrm{cm}$ of soil). Samples were sieved to 63 microns to minimize the effect of grain size variations in $\mathrm{Pb}$ concentration. Dried soils were ashed at $550^{\circ} \mathrm{C}$ and digested for $2 \mathrm{~h}$ in warm $\left(90^{\circ} \mathrm{C}\right) 3 \mathrm{~N}$ trace metal grade hydrochloric acid. Supernatants were diluted with ultra-pure water (MilliQ) and analyzed via inductively coupled plasma-atomic-emission spectrometry.
All digestions were run with National Institute of Standards and Technology (NIST) soil standards for reference. Replicates were also run for all analyses, with typical analytical reproducibility of $\sim 2 \%$. Additional details and results for a number of other trace metals can be found in Laidlaw (2001).

\section{ROADWAY SOURCES OF Pb}

The aerosolized combustion products (containing $\mathrm{Pb}$ ) from the burning of leaded gasoline in internal combustion engines initially deposit within $\sim 50 \mathrm{~m}$ of a roadway if no obstructions are present (Fig. 2). The fate of deposited $\mathrm{Pb}$ then depends on the conditions of the depositional area. Although intersections of busy streets may have received over one metric ton of $\mathrm{Pb}$ per year (Mielke et al., 1997), their impervious surfaces lead to continual runoff of $\mathrm{Pb}$-enriched particulates down storm drains (and from there into treatment plants or directly into rivers). If the particulate $\mathrm{Pb}$ is deposited instead on a grassy fringe, like a front yard or park, the $\mathrm{Pb}$ can be effectively retained. In such a setting, the insolubility of $\mathrm{Pb}$ leads to surface peaks in $\mathrm{Pb}$ concentration of soils (Fig. 3); in relatively undisturbed soils, this surface $\mathrm{Pb}$ enrichment may be the product of decades of $\mathrm{Pb}$ deposition from gasoline and may reach levels above 1000 ppm (Mielke, 1999; Mielke et al. 2003).

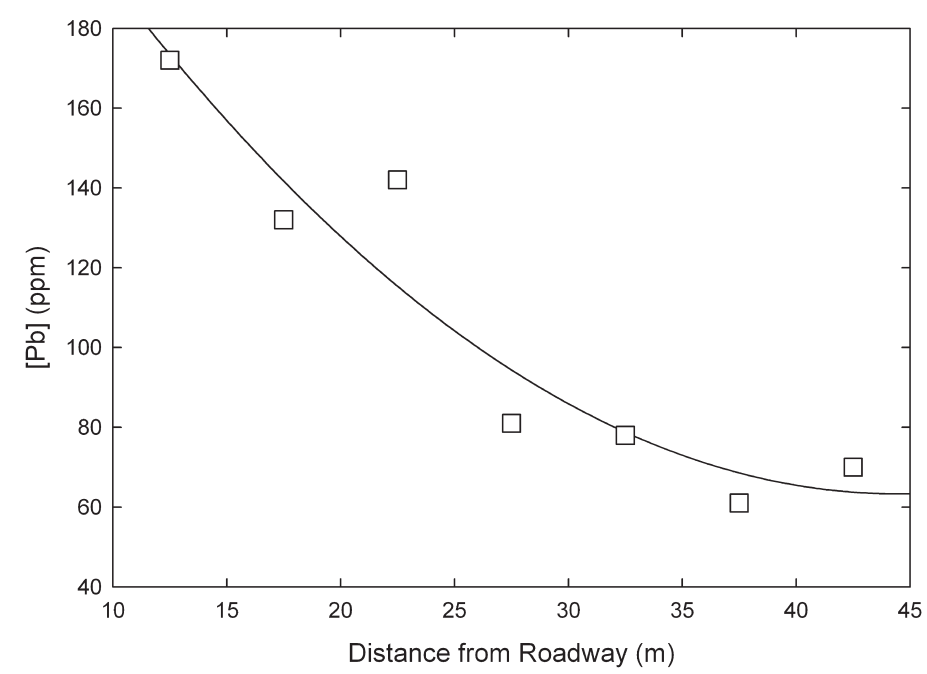

Figure 2. The exponential decay of $\mathrm{Pb}$ in surface soils as a function of distance from a roadway source along a suburban street in Indianapolis, Indiana (Kessler Boulevard). This curve is typical of the roadway effect, showing both the rapid deposition of $\mathrm{Pb}$ in exhaust particulates from the combustion of leaded gasoline and the persistence of this $\mathrm{Pb}$ in surface soils (leaded gasoline use stopped $\sim 20 \mathrm{yr}$ ago). A second-order regression fits data the best, yielding a correlation coefficient $\left(r^{2}\right)$ of 0.902 . Symbol size is larger than error bars on both axes.
The roadway $\mathrm{Pb}$ generally is partitioned into the highly bioavailable carbonate, iron, and manganese hydroxide soil fractions, while the natural $\mathrm{Pb}$ in soils is speciated in the residual, or nonbioavailable fractions (Chlopecka et al., 1996; Lee et al., 1997). Lead is associated with the smallest particles, the clay grain size fraction in urban soils (Dong et al., 1984). Therefore, dust originating from urban soils contaminated by anthropogenic $\mathrm{Pb}$ is more toxic than naturally occurring dust and is more potent and concentrated than would be expected from simple measurements of the $\mathrm{Pb}$ content of the soil (Young et al., 2002).

\section{DIFFUSE SOIL Pb AND CHILDREN'S HEALTH-A CASE STUDY FROM INDIANAPOLIS}

The original sources of $\mathrm{Pb}$ to the environment were distinct sources, including Pb-based paints, gasolineemitted $\mathrm{Pb}$, and $\mathrm{Pb}$ emitted from smelters. As detailed above, $\mathrm{Pb}$ does not originally deposit far from its source, and its geochemical characteristics promote rapid sequestration onto surface soil particulates (usually via surface complexation of $\mathrm{Pb}$ and $\mathrm{Pb}$ oxides with soil organic matter). But an analysis of many urban areas reveals that these point sources have, to some extent at least, been redistributed to produce regions of $\mathrm{Pb}$ enrichment. Several factors can lead 


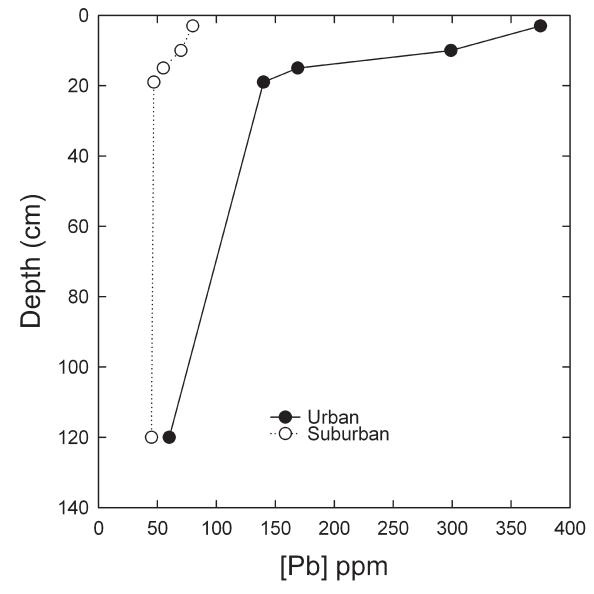

Figure 3. Concentration of $\mathrm{Pb}$ as a function of depth from two soil cores in Indianapolis, displaying the surface peak in both an urban and suburban settings far from direct sources of $\mathrm{Pb}$ deposition (e.g., painted structures or roads). This plot shows a soil background level of 50 ppm $\mathrm{Pb}$ (consistent with geological materials) and the surface retention of $\mathrm{Pb}$, but also displays the ambient diffuse soil $\mathrm{Pb}$ enrichment in urban versus suburban areas. Sampling locations are in Laidlaw (2001).

to redistribution of $\mathrm{Pb}$-enriched particles and soil-this issue will be addressed more completely in the next sectionbut the recurrence of a general urban enrichment of soil $\mathrm{Pb}$ has been documented in many regions (e.g., Mielke et al., 1983), and the potential impacts of this urban contamination were presaged by the classic quote by Clair Patterson (NAS, 1980), "Sometime in the near future it probably will be shown that the older urban areas of the United States have been rendered more or less uninhabitable by the millions of tons of poisonous industrial $\mathrm{Pb}$ residues that have accumulated in cities during the past century." To explore this generalized urban enrichment, termed diffuse soil $\mathrm{Pb}$, and evidence of its potential human health impact, we first show the pattern of diffuse soil $\mathrm{Pb}$ in Indianapolis, then the link between soil $\mathrm{Pb}$ and children's blood $\mathrm{Pb}$ levels.

One of the characteristics of $\mathrm{Pb}$ distribution in the surface soils of cities is a distinct decrease in concentration from the city center to suburban surroundings (Mielke, 1999), a legacy both of $\mathrm{Pb}$ deposition, redistribution, and smearing of original point sources, and less $\mathrm{Pb}$ deposition in newer suburban neighborhoods due to recent $\mathrm{Pb}$ controls. This urban-suburban gradient can be illustrated by examining diffuse soil $\mathrm{Pb}$ along an urban roadway transect (Washington Street) versus one in the suburbs (East Kessler Blvd.) of Indianapolis. Washington Street, the route of the National Road (U.S. 40) in Indianapolis, experiences high local traffic loads and is bordered by very old urban neighborhoods. In contrast, the suburban East Kessler Boulevard was developed from a country road to a suburban thoroughfare in the 1970s, during a time when the use of leaded gasoline was declining significantly (Fig. 1). In the reference year 1980 (the official phase-out of leaded gas was 1986 , although most vehicles were running on unleaded fuel by 1981), East Kessler Boulevard experienced a relatively high daily traffic load, but only $~ 50 \%$ that of Washington Street at the westernmost intersection. A comparison of the $\mathrm{Pb}$ loading from roadway sources along these two streets reveals three main factors of roadway $\mathrm{Pb}$ deposition. First, the decrease in $\mathrm{Pb}$ concentration away from the roadway is manifest in both higher and lower traffic volume settings (Fig. 4). Second, although leaded gasoline use spanned a relatively short time along the suburban roadway, the legacy of this deposited roadway $\mathrm{Pb}$ remains, attesting to the immobility of $\mathrm{Pb}$ after deposition. Finally and most critically, the urban roadway example shows both the impact of the long-term $\mathrm{Pb}$ loading from leaded gasoline close to the road-

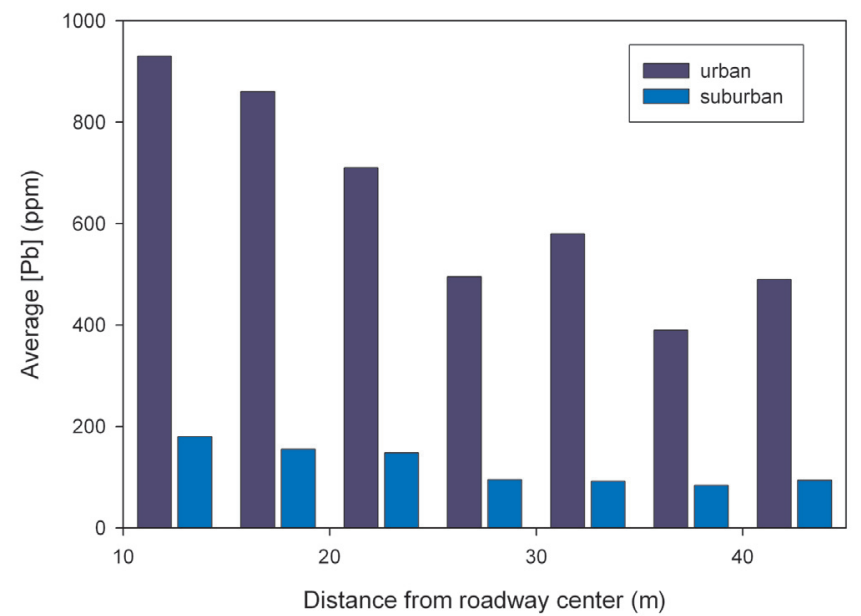

Figure 4. Average $\mathrm{Pb}$ concentrations in surface soil as a function of distance from the roadway using the urban Washington Street and suburban East Kessler Boulevard transects. The decrease away from the roadway source is apparent, but more importantly, there are significantly higher values in the urban transect, even at distances up to $42.5 \mathrm{~m}$ from the road center, beyond the range of direct deposition of $\mathrm{Pb}$ particulates from the combustion of leaded gasoline. Additionally, the significant near-roadway loading of surface soils in the urban transect is reflective of higher daily traffic volumes and the much greater duration of the urban roadway as an important traffic artery. way as well as the diffuse soil $\mathrm{Pb}$ that blankets urban regions (Fig. 4). In other way beyond where direct $\mathrm{Pb}$ deposition occurs (and far away from structures using Pb-based paint), the background level for $\mathrm{Pb}$ is significantly higher in the urban transect $(\sim 500 \mathrm{ppm})$ than in the suburban transect ( $60 \mathrm{ppm})$. This urban-suburban gradient is one overriding factor affecting the amount of $\mathrm{Pb}$ loading to individuals, a factor that we will next assess on a larger scale and with respect to human health.

\section{Children's Blood Pb Levels and Diffuse Soil Pb}

In many urban areas of older cities, large segments of children below the age of six have venous blood $\mathrm{Pb}$ levels exceeding the action level of $10 \mu \mathrm{g} / \mathrm{dL}$ (e.g., Mielke, 1999)—such is the case in Indianapolis. The actual distribution of blood $\mathrm{Pb}$ levels exceeding action limits is getting more difficult to obtain due to privacy issues, but in the past, blood $\mathrm{Pb}$ values could be collected from health department records down to the level of a street address, providing an outstanding way to examine the environmental factors in human health. The address-level distribution of blood $\mathrm{Pb}$ levels exceeding action limits in Indianapolis from 1992 to 1994 is informative. Much of the higher blood $\mathrm{Pb}$ values are concentrated in urban areas, particularly downtown. In contrast, very words, even at distances from the road- 


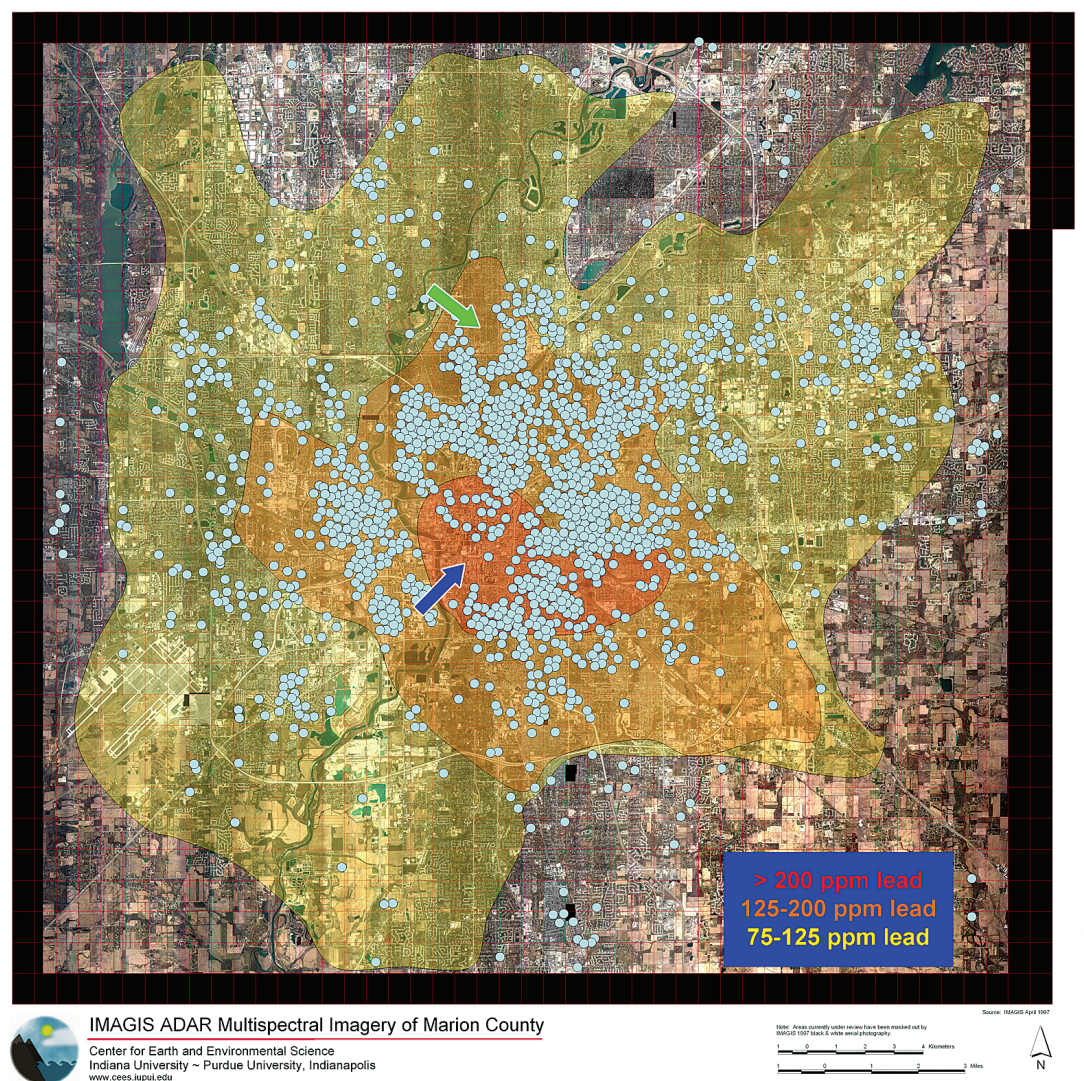

Figure 5. Satellite infrared image of Indianapolis, central Indiana (the boundaries are the Marion County borders - the city of Indianapolis officially extended its boundaries to those of the county in 1970). The concentration of diffuse soil Pb in surface soils of Indianapolis (colored regions) displays a characteristic pattern of urban enrichment trending toward background values in suburban and agricultural regions. The overprint of high diffuse soil $\mathrm{Pb}$ presented here corresponds roughly to the distribution of elevated blood $\mathrm{Pb}$ levels in children, displayed as circles for the distribution of children's venous blood samples exhibiting $\mathrm{Pb}$ concentrations above the level of concern $(10 \mu \mathrm{g} / \mathrm{dL})$ from 1992 to 1994 in Indianapolis. Most elevated blood samples are from the downtown region (significant overlap of multiple positive results occur in this region), with some additional scattered positive results ranging toward the older suburban development to the west and the east. These trends in positive samples are not dominantly controlled by population density, as the northern corridor and northeast portion of Indianapolis have population densities similar to those in the central urban region. The arrows point to regions with high diffuse soil $\mathrm{Pb}$ but low incidence of $\mathrm{Pb}$ poisoning, at apparent odds with the direct link between soils and blood. As with all epidemiological processes, a number of factors act as filters between potential exposure and toxicology, like socioeconomic status, age, population distribution, etc. In the case of the blue arrow, the lack of $\mathrm{Pb}$ poisoning is due to the lack of habitations in this industrial corridor, while the green arrow highlights a main street that displays a socioeconomic divide between poverty-line neighborhoods in the near-urban area and upper-middle and upper-class neighborhoods in the northern suburban area.

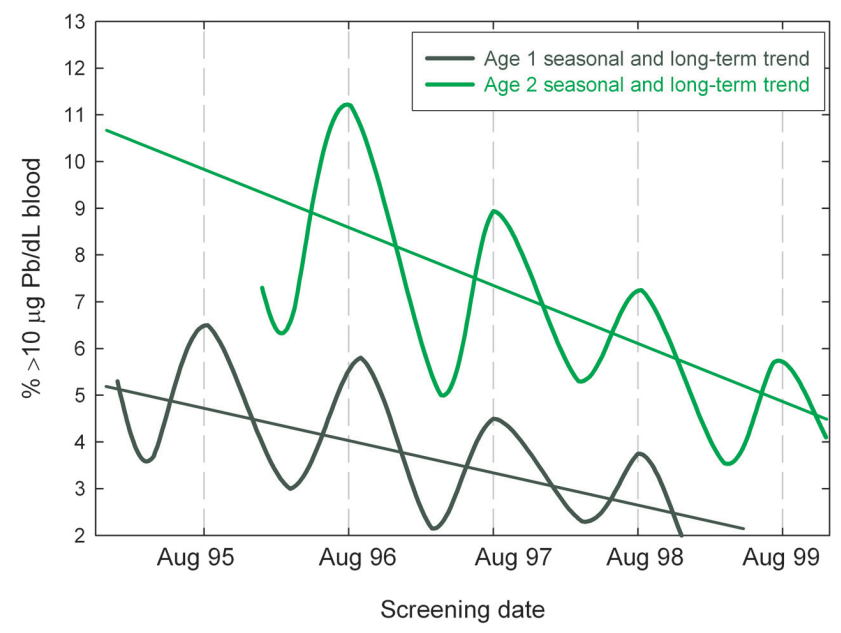

few incidences of blood $\mathrm{Pb}$ poisoning are found in the newer suburban areas to the west, north, south, and northeast sides of the city (Fig. 5). Because these are individual blood $\mathrm{Pb}$ data, population density plays some role in the distribution; for example, rural farmlands on the city outskirts have few incidences. But based on the 1999-2000 U.S. Census (Laidlaw, 2001), the population density per census tract in the newer suburban areas with few blood $\mathrm{Pb}$ poisoning incidences is comparable to the urban and near-urban areas with a high incidence.

To explore the concept of diffuse soil $\mathrm{Pb}$ (i.e., $\mathrm{Pb}$ now present far away from its initial depositional area) and its potential role in affecting children's health (e.g., Lanphear et al., 1998), we carefully selected sampling locations throughout Indianapolis. Our sampling criteria included soil $>50 \mathrm{~m}$ from roadways and from structures (which might have contributed Pb-based paint), and was augmented by aerial photographic records over Indianapolis from several time slices (1940, 1970). The purpose of these aerial photographs was to rule out the potential for inadvertently sampling soils from disturbed, excavated, or filled areas that might have surface $\mathrm{Pb}$ contents characteristic of artificial materials rather than ambient soil. As one can imagine in a rapidly developing urban area, these criteria narrowed acceptable sites to only $\sim 100$ distinct sites (because of tillage, even the agricultural sites were excluded). Many of the acceptable sites were in parks, cemeteries, and very large lawns. Analyses were also carried out to determine whether soil source material showed any inherent $\mathrm{Pb}$ variation. The soil in Marion County (the area surrounding and including Indianapolis) is glacial outwash, till, and alluvium with a variety of lithologies including limestone, shale, and
Figure 6. Seasonal patterns in children's blood Pb levels from New York State, showing summer peaks and a general decline from 1995 to 1999 (after Haley and Talbot, 2004). Note the generally higher levels of $\mathrm{Pb}$ poisoning in two-year-olds ("Age $2^{\prime \prime}$ ), who are generally more mobile with consequently greater hand exposure to $\mathrm{Pb}$-contaminated surfaces and more access to the outdoors. 
granite. No trend was found between $\mathrm{Pb}$ content and soil composition across Marion County (Laidlaw, 2001), and thus we suggest that soil mineralogy is a minor control on the $\mathrm{Pb}$ distributions presented here.

In contrast to roadway and houseside soil sampling, which might exhibit $\mathrm{Pb}$ concentrations above 1000 ppm, the highest soil $\mathrm{Pb}$ concentrations in our study were below 500 ppm. The lowest $\mathrm{Pb}$ concentrations averaged $\sim 50$ ppm, which is a typical value for soils in this region based on a comparison to selected rural sites (Fig. 3; Laidlaw, 2001) and which we consider here the geological background value. As expected, the highest soil $\mathrm{Pb}$ concentrations were centered directly over the old urban and industrial areas of Indianapolis (Fig. 5), where the diffuse soil $\mathrm{Pb}$ content averaged $\sim 200 \mathrm{ppm}$. Beyond this central hot spot, Pb concentrations decreased systematically toward the suburban outskirts of the city, ultimately falling to background values in the rural fringes of the city (Fig. 5). The central peak is consistent with the long history of $\mathrm{Pb}$ use in the downtown area, but the generally high values even away from point sources support the argument of a redistribution of $\mathrm{Pb}$ over time. This is a common feature of urban $\mathrm{Pb}$ distribution (e.g., Mielke, 1999), and it is likely related to the wind-driven redistribution of fine $\mathrm{Pb}$-enriched particulates in a statistically consistent pattern (e.g., a two-dimensional exponential decay curve) over decades.

Combining the distribution of soil $\mathrm{Pb}$ with that of children's blood $\mathrm{Pb}$ poisoning reveals several important characteristics of diffuse soil $\mathrm{Pb}$ as a potential contributor to children's health problems. First, the similarity in the distribution of elevated soil and blood $\mathrm{Pb}$ values downtown reveals the potential for diffuse soil $\mathrm{Pb}$ to be an additional and important factor in children's blood $\mathrm{Pb}$ levels. Second, population patterns definitely have some influence on the health distribution data. For example, some areas downtown have perhaps the highest concentration of diffuse soil $\mathrm{Pb}$ but surprisingly few incidences of $\mathrm{Pb}$ poisoning (blue arrow on Fig. 5); in this case, this is because this region is an industrial area with no housing.
In another case, the lack of correlation between soil $\mathrm{Pb}$ and blood $\mathrm{Pb}$ corresponds with a very high socioeconomic status in a wealthy northside neighborhood (green arrow on Fig. 5).

Although many factors influence the relationship between geology and human health in the story of $\mathrm{Pb}$, it is clear from the lack of closure on this issue that we do not yet understand all of the contributing factors. Furthermore, the generalized approach presented above provides a reference point for further work, but does not integrate health data and geologic data well, nor does it present clear recommendations that geologists can make to health specialists in further reducing this public health hazard beyond the incredibly costly and disruptive solution of removing all of the contaminated surface soil in urban areas and replacing it with clean fill. Several bridging efforts are now being pursued to help further medical geology in the context of eliminating childhood $\mathrm{Pb}$ poisoning. Beyond simply documenting $\mathrm{Pb}$ distribution and its public health implications, current research is also examining more closely $\mathrm{Pb}$ as a toxicological agent with predictable behavior. For example, isotopic techniques have been utilized to closely examine the entry mechanisms of $\mathrm{Pb}$ into the body and the cycling of $\mathrm{Pb}$ within the body (e.g., Maddaloni et al., 1998; Gwiazda and Smith, 2000), with a goal of pinpointing the source of $\mathrm{Pb}$ toxicity in individuals and thus more closely coupling prevention and treatment. Another new tool of promise in accurately assessing $\mathrm{Pb}$ poisoning is predictive modeling of children's blood $\mathrm{Pb}$ levels using climatologic data.

\section{CLIMATIC FACTORS AND A BLOOD Pb PREDICTIVE MODEL FOR HEALTH CARE RESEARCH}

Several studies have identified a seasonal trend in blood $\mathrm{Pb}$ levels, with average monthly blood $\mathrm{Pb}$ levels of children from urban areas increasing significantly in summer months (Rabinowitz and Needleman, 1982; Hwang and Wang, 1990; Johnson et al., 1996; Mielke and Reagan, 1998; Yiin et al., 2000; Johnson and Bretsch, 2002; Haley and Talbot, 2004), perhaps partly due to increased exposure to Pb-based paint on window sills and through increased contact with soils containing $\mathrm{Pb}$ during the summer. A positive in this trend is that, overall, children's blood $\mathrm{Pb}$ values continued to decrease through the 1990s, but the seasonal trend in values seen in comprehensive studies is still a striking feature (Fig. 6). Summer increases of children's blood Pb levels were so prominent over many years in Syracuse, New York, that the researchers concluded that the phenomena was probably caused by the interaction between climate and soils (Johnson et al., 1996; Johnson and Bretsch, 2002), leading to enhanced dust $\mathrm{Pb}$ loading to children. An intriguing alternative hypothesis for blood $\mathrm{Pb}$ seasonality is internal, whereby bone material is increasingly recycled during summer months, releasing stored $\mathrm{Pb}$ to the blood stream (Rothenberg et al., 2001). Additionally, the increased amount of time that children spend outdoors in the summer when school is out may lead to increased exposure to $\mathrm{Pb}$ in soil.

To better constrain this possible climate-soil-human health link, we have been investigating in detail variations in children's blood $\mathrm{Pb}$ levels as a function of climate and soil factors in several urban areas. The ultimate goal of this effort is to develop a predictive model whereby a medical researcher can make an accurate diagnosis of $\mathrm{Pb}$ poisoning based on seasonal and weather-related factors as well as blood $\mathrm{Pb}$ level data. With a focus on Indianapolis (ongoing analyses are also being conducted in several other cities, with similar results as those presented here), we used a number of climatologically independent variables, including average monthly soil moisture, particulate matter $<10$ microns in size (PM10), wind speed, and temperature obtained from state and federal government data sources. We also used blood $\mathrm{Pb}$ databases obtained from local and state governmental sources and averaged them monthly (Fig. 7).

Based on this multiple regression model, and unpublished results from several other American cities, we believe that the seasonality in children's blood Pb levels (Fig. 7) is controlled by exposure to $\mathrm{Pb}$ dust originating from contaminated soils and suspended in the air when several weather-related environmental conditions are present: 


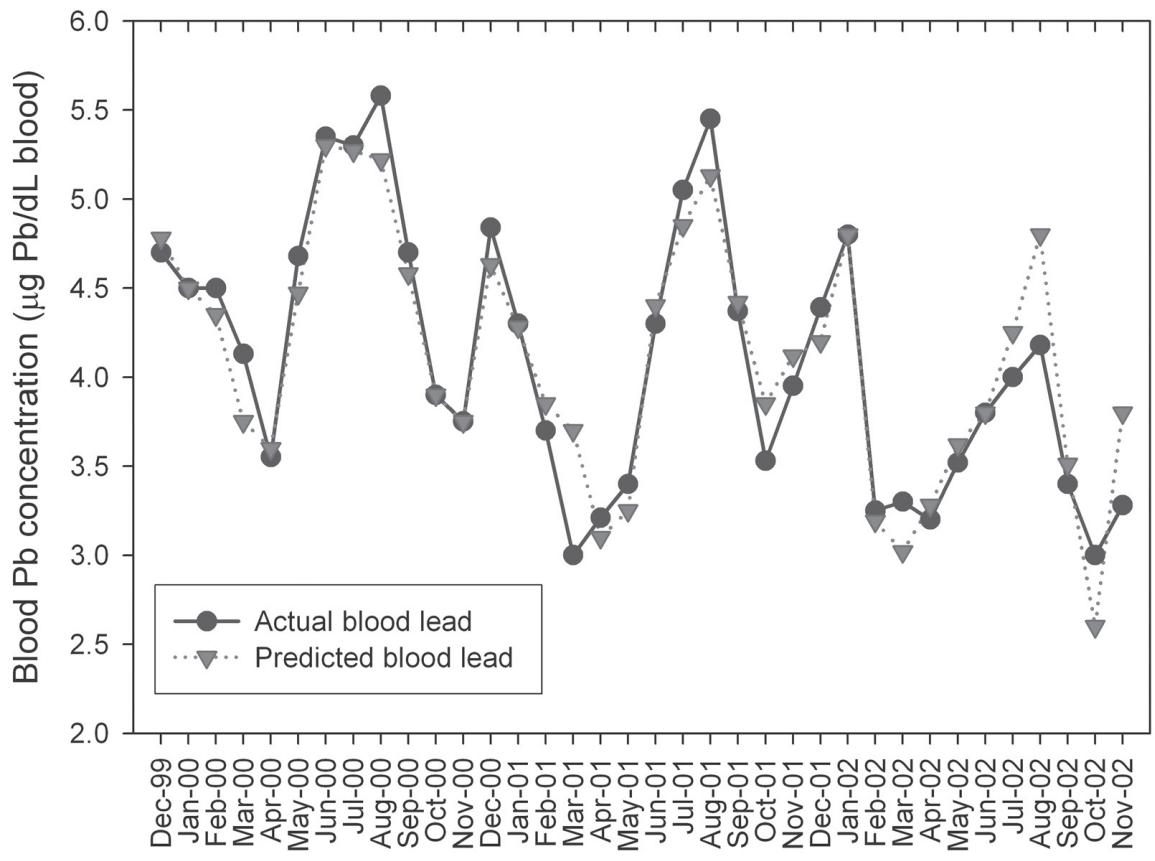

Month and year

high temperature, low soil moisture, and elevated atmospheric PM10. When temperature is high and evapotranspiration is maximized, soil moisture becomes low, and the generation of soil dust is maximized. Under these combined weather conditions, Pb-enriched PM10 dust disperses in the urban environment and is manifest by elevated $\mathrm{Pb}$ dust loading. In this case, exposure is via increased dust loads in homes and on contact surfaces, with ingestion as the uptake mechanism. Although further work using detailed tracking of $\mathrm{Pb}$, possibly involving $\mathrm{Pb}$ isotopic studies as outlined above, may help to elucidate the connection between seasonality and blood $\mathrm{Pb}$ values, we argue that the ability of geochemical and meteorological factors to predict blood $\mathrm{Pb}$ supports our supposition that external loading and exposure drives much of the blood $\mathrm{Pb}$ concentrations.

In addition to the development of hypotheses related to the incorporation of $\mathrm{Pb}$ into children's systems, a promising result of these modeling analyses is the ability to predict toxicity in a given population. In other words, through easily collected atmospheric and soil
Figure 7. Best-fit model results to predict blood $\mathrm{Pb}$ levels (BLLs) in children from Indianapolis compared to actual monthly average BLLs. This type of effort can be used to better treat $\mathrm{Pb}$ poisoning from a public health perspective by providing clinicians with predicted trends of BLLs (functionally calculated as a percent deviation from the mean) at a given blood sampling event, allowing them to calculate the potential increase or decrease with time given normal exposure. Twelve separate multiple linear regression models, not presented in this paper, were modeled and differed only in the dependent variable. The independent variables for each model consisted of soil moisture, wind speed, particulate matter $<10$ microns in size (PM10), temperature, atmospheric $\mathrm{Pb}$, interaction variables, and monthly dummy variables (M1 to M11). The time period of the regression consisted of 36 months between December 1999 and November 2002. The dependent variables for the models included monthly child blood $\mathrm{Pb}$ data from (1) a variety of subregions in Indianapolis, (2) a variety of BLLs, and (3) a variety of ages (i.e., $0-1.0$, 1.01-2.0, 2.01-3.0, 3.01-4, 4.01-5, and 5.01-7.0 yr). The blood $\mathrm{Pb}$ database totals during this time interval included a monthly child blood $\mathrm{Pb}$ data set of 15,969 children. The outcome variable, children's average monthly city blood $\mathrm{Pb}$ concentration, was regressed against the average monthly independent variables soil moisture, PM10, wind speed, temperature, interaction variables, and monthly dummy variables using backward elimination procedures. The dominant wind direction in Indianapolis is east-southeast (Laidlaw, 2001), but in our initial analysis, wind direction had no predictive application for blood $\mathrm{Pb}$ values. This model indicates that the variables or interaction variables including soil moisture, wind speed, PM10, temperature, and the monthly dummy variables for March through September explain $87 \%$ of the variation in the response variable, monthly average child BLL concentration (correlation coefficient, $\mathrm{r}^{2},=0.87$; number of individuals $=15,969$ ).

of them from lower socioeconomic minority households. In this paper, we highlighted the persistence of $\mathrm{Pb}$ in surface soils as a potential route for the continued poisoning of urban youth, with socioeconomic status being a large contributor to the problem in areas with high ambient soil $\mathrm{Pb}$. Although education and remediation seems to show continuing health benefits, it is likely that we will have to adopt another strategy, including soil $\mathrm{Pb}$ and soil dust exposure, to get over the final hurdle and eradicate $\mathrm{Pb}$ poisoning in this country. This strategy might include 
funded programs focused on aggressive landscaping of urban soils that are implicated in $\mathrm{Pb}$ poisoning, including mulching, geotextile barriers, dilution of soil $\mathrm{Pb}$ with added clean top soil, or construction projects like decking installation to remove children and their homes from exposure to Pb-enriched dust and soils. By collecting data and designing studies that more directly inform the health sciences community, particularly with the application of spatially-referenced studies and $\mathrm{Pb}$ isotopic techniques, researchers in the field of medical geology may have an important part to play in improving the short and long-term health of urban youth.

\section{ACKNOWLEDGMENTS}

We would like to thank the early and continued inspiration from $\mathrm{H}$. Mielke and D. Johnson, students in a variety of courses at Indiana University-Purdue University Indianapolis who have contributed intellectually and physically to this work, and David Bivin for statistical assistance, including the suggestion of the monthly dummy variables to increase modeling significance. Reviews by W. Berry Lyons, Thomas Ziegler, Jeff Chiarenzelli, Samuel Bowring, and Gerry Ross improved this manuscript substantially.

\section{REFERENCES CITED}

Agency for Toxic Substances and Disease Registry [ATSDR], 2002, Pediatric environmental health: Case studies in environmental medicine: Atlanta, Georgia, ATSDR Publication no. ATSDR-HE-CS-2002-0002, 88 p

Bernard, S.M., 2003, Should the Centers for Disease Contro and Prevention's childhood lead poisoning intervention level be lowered?: American Journal of Public Health, v. 93 p. $1253-1260$

Brody, D.J., Pirkle, J.L., Kramer, R.A., Flegal, K.M., Matte, T.D., Gunter, E.W., and Paschal, D.C., 1994, Blood lead levels in the U.S. population. Phase 1 of the Third National Health and Nutrition Examination Survey (NHANES III, 1988 to 1991): Journal of the American Medical Association, v. 272, p. 277-283, doi: 10.1001 jama.272.4.277.

Brown, M.J, and Meehan, PJ.,2004, Health effects of blood lead levels lower than $10 \mu \mathrm{g} / \mathrm{dL}$ in children: American Journal of Public Health, v. 94, p. 8-9.

Bryson, B., 2003, A short history of nearly everything: New York, Broadway Books, $560 \mathrm{p}$

Chlopecka, A., Bacon, J.R., Wilson, M.J., and Kay, J., 1996, Forms of cadmium, lead, and zinc in contaminated soils from southwest Poland: Journal of Environmental Quality, v. 25, p. $69-79$

Deboudt, K., Flament, P., Weis, D., Mennessier, J.P., and Maquinghen, P., 1999, Air pollution sources assessment using the lead isotopic signature technique: The Science of the Total Environment, v. 236, p. 57-74, doi: 10.1016/S00489697(99)00286-7.

Dong, A., Chesters, G., and Simsiman, G.V., 1984, Metal composition of soil, sediments, and urban dust and dirt samples from the Menomonee River Watershed, Wisconsin U.S.A.: Water, Air, and Soil Pollution, v. 22, p. 257-275, doi 10.1007/BF00159348.
Graziano, J.H., Blum, C.B., Lolacono, N.J., Slavkovich V., Manton, W.I., Pond, S., and Moore, M.R., 1996, A human in vivo model for the determination of lead bioavailability using stable isotope dilution: Environmental Health Perspectives, v. 104, p. 176-179.

Gwiazda, R., and Smith, D.R., 2000, Lead isotopes as a supplementary tool in the routine evaluation of household lead hazards: Environmental Health Perspectives, v. 108 p. 1091-1097.

Haley, V.B., and Talbot, T.O., 2004, Seasonality and trend in blood lead levels of New York State children: BMC Pediatrics, v. 4, p. 8, doi: 10.1186/1471-2431-4-8

Hong, S., Candelone, J.-P., Patterson, C.C., and Boutron, C.F., 1994, Greenland ice evidence of hemispheric lead pollution two millennia ago by Greek and Roman civilizations: Science, v. 265, p. 1841-1843.

Hwang, Y.-H., and Wang, J.-D., 1990, Temporal fluctuation of the lead level in the cord blood of neonates in Taipei: Archives of Environmental Health, v. 45, p. 42-45.

Johnson, D., and Bretsch, J., 2002, Soil lead and children's BLL Levels in Syracuse, NY, USA: Environmental Geochemistry and Health, v. 24, p. 375-385, doi: 10.1023/ A:1020500504167.

Johnson, D., McDade, K., and Griffith, D., 1996, Seasonal variation in pediatric blood levels in Syracuse NY, USA: Environmental Geochemistry and Health, v. 18, p. 81-88.

Koller, K., Brown, T., Spurgeon, A., and Levy, L., 2004, Recent developments in low-level lead exposure and intellectual impairment in children: Environmental Health Perspectives, v. 112, p. 987-994.

Kurkjian, R., and Flegal, R.A., 2003, Isotopic evidence of the persistent dominance of blood lead concentration by previous gasoline lead emission in Yerevan, Armenia: Environmental Research, v. 93, p. 308-315, doi: 10.1016 S0013-9351(03)00066-5.

Laidlaw, Mark, 2001, Distribution and sources of metals in soils of Marion County, Indiana [M.S. Thesis]: Indianapolis, Indiana University, $175 \mathrm{p}$.

Lanphear, B.P., Matte, T.D., Rogers, J., Clickner, R.P. Dietz, B, Bornschein, R.L., Succop, P. Mahaffey, K.R Dixon, S., Galke, W., Rabinowitz, M., Farfel, M., Rohde, C., Schwartz, J., Ashley, P., and Jacobs, D.E., 1998, The contribution of lead-contaminated house dust and residential soil to children's blood lead levels. A pooled analysis of 12 epidemiologic studies: Environmental Research, v. 79 , p. 51-68, doi: 10.1006enrs.1998.3859.

Lee, P.-K., Touray, J.-C., Bailiff, P., and Ildefonse, J.-P., 1997 Heavy metal contamination of settling particles in a retention pond along the A-71 motorway in Sologne, France: The Science of the Total Environment, v. 201, p. 1-15, doi 10.1016/S0048-9697(97)84048-X

Maddaloni, M., Lolacono, N., Manton, W., Blum, C., Drexler, J., and Graziano, J., 1998, Bioavailability of soil-borne lead in adults by stable isotope dilution: Environmental Health Perspectives, v. 106, p. 1589-1594.

Manton, W.I., Angle, C.R., Stanek, K.L., Reese, Y.R., and Kuehnemann, A.J., 2000, Acquisition and retention of lead by young children: Environmental Research, v. 82, p. 6080, doi: 10.1006/enrs.1999.4003.

Markowitz, G., and Rosner, D., 2002, Deceit and denial: The deadly politics of industrial pollution: Berkeley, University of California Press, 428 p.

Mathee, A., Schirnding, Y.E.R., Levin, J., Ismail, A., Huntley, R., and Cantrell, A., 2002, A survey of blood lead levels among young Johannesburg school children: Environmental Research, v. 90, p. 181-184.

Mielke, H.W., 1999, Lead in the inner cities: American Scientist, v. 87, p. 62-69, doi: 10.1511/1999.1.62.

Mielke, H.W., and Reagan, P., 1998, Soil is an important pathway of human lead exposure: Environmental Health Perspectives, v. 106, supplement 1, p. 217-229.

Mielke, H.W., Anderson, J.C., Berry, K.J., Mielke, P.W. Jr. and Chaney, R.L., 1983, Lead concentrations in inner-city soils as a factor in the child lead problem: American Journa of Public Health, v. 73, p. 1366-1369.

Mielke, H.W., Dugas, D., Mielke, P.W. Jr., Smith, K.S. and Conzales, C.R., 1997, Associations between soil lead and children's blood lead in urban New Orleans and rural Lafourch Parish of Louisiana: Environmental Health Perspectives, v. 105, p. 950-954.
Mielke, H.W., Gonzales, C., Powell, E., Coty, S., and Shah, A., 2003, Anthropogenic distribution of lead, in Skinner, H.C.W., and Berger, A.R., eds., Geology and health: Closing the gap: New York, Oxford University Press, p. 119-124. National Academy of Sciences [NAS], 1980, Lead in the human environment: Committee on lead in the human environment: Washington, D.C., National Academy of Sciences, p. 265-349.

National Heath and Nutrition Examination Survey [NHANES], 2003, Centers for Disease Control and Prevention, http://www.cdc.gov/nchs/about/major/nhanes/ nhanes99-02.htm, Accessed 15 Aug. 2004.

Rabinowitz, M.B., and Needleman, H.L., 1982, Temporal trends in the lead concentration of umbilical cord blood: Science, v. 216, p. 1429-1431.

Rabito, F.A., Shorter, C., and White, L.E., 2003, Lead levels among children who live in public housing: Epidemiology (Cambridge, Massachusetts), v. 14, p. 263-268.

Roberts, J.R., Reigert, J.R., Eberling, M., and Hulsey, T.C. 2001 , Time required for blood lead levels to decline in nonchelated children: Journal of Toxicology, Clinical Toxicology, v. 39, p. 153-160, doi: 10.1081/CLT-100103831.

Rosman, K.J., Chisholm, W., Hong, S., Candelone, J.-P., and Boutron, C.F., 1997, Lead from Carthaginian and Roman Spanish mines isotopically identified in Greenland ice dated from 600 B.C. to 300 A.D. Environmental Science \& Technology, v. 31, p. 3413-3416., doi: 10.1021/es970038k. Rothenberg, S.J., Kondrashov, V., Manalo, M., Manton, W.I., Khan, F., Todd, A.C., and Johnson, C., 2001, Seasonal variation in bone lead contribution to blood lead during pregnancy: Environmental Research, v. 85, p. 191-194, doi: 10.1006/enrs.2000.4238.

Sañudo-Wilhelmy, S.A., and Gill, G.A., 1999, Impact of the Clean Water Act on the levels of toxic metals in urban estuaries: The Hudson River estuary revisited: Environmental Science \& Technology, v. 33, p. 3477-3481, doi: 10.1021/ es981130z.

Settle, D.M., and Patterson, C.C., 1980, Lead in albacore: Guide to lead pollution in Americans: Science, v. 207, p. 1167-1176.

Young, T.M., Heerman, D.A., Sirin, G., and Ashbaugh, L.L., 2002, Resuspension of soil as a source of airborne lead nea industrial facilities and highways: Environmental Science \& Technology, v. 36, p. 2484-2490, doi: 10.1021/es015609u.

Yiin, L., Rhoads, G., and Lioy, P., 2000, Seasonal influences on childhood lead exposure: Environmental Health Perspectives, v. 108, p. 177-182.

Ziegler, E.E., Edwards, B.B., Jensen, R.L., Mahaffey, K.R and Foman, S.J., 1978, Absorption and retention of lead by infants: Pediatric Research, v. 12, p. 29-34.

Manuscript received 21 September 2004; accepted 1 November 2004. $:$

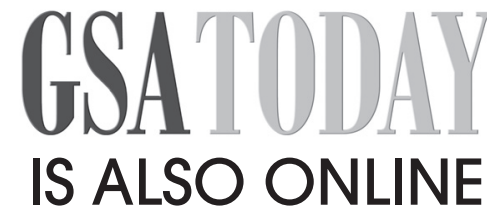

To view GSA Today online, go to www.gsajournals.org and click on

"Online Journals" then on the cover of GSA Today. You can also view back issues through the "Archives" button. Access to GSA Today online is free. 